\title{
Incidental right Bochdalek hernia with interruption of the inferior vena cava and hepatic venous collateral continuation: A case report
}

\author{
Authors: \\ Farzanah I. Ismail ${ }^{1}$ \\ Rule Human ${ }^{2}$ \\ Anith Chacko ${ }^{1}$ \\ Parmanand Naran ${ }^{2}$ \\ Samia Ahmad ${ }^{1}$ \\ Siraj Ellemdin ${ }^{2}$
}

\section{Affiliations:}

${ }^{1}$ Department of Radiology,

Steve Biko Academic Hospital and University of Pretoria,

South Africa

${ }^{2}$ Department of Internal Medicine, Steve Biko Academic Hospital and University of Pretoria, South Africa

Correspondence to:

Farzanah Ismail

Email:

drfismail@yahoo.com

\section{Postal address:}

Level 5, Bridge E, Steve

Biko Academic Hospital,

Voortrekker Road, Gezina,

Pretoria 0002, South Africa

Dates:

Received: 09 Nov. 2013

Accepted: 05 Dec. 2013

Published: 30 May 2014

How to cite this article: Ismail FI, Human R, Chacko A, Naran P, Ahmad S, Ellemdin S. Incidental right Bochdalek hernia with interruption of the inferior vena cava and hepatic venous collateral continuation: A case report. S Afr J Rad. 2014;18(1); Art. \#592, 3 pages. http://dx.doi. org/10.4102/sajr.v18i1.592

\section{Copyright:}

C 2014. The Authors.

Licensee: AOSIS

OpenJournals. This work

is licensed under the

Creative Commons

Attribution License.

\section{Read online:}

A 36-year-old asymptomatic female had a routine chest radiograph to exclude pulmonary tuberculosis, as part of an employee wellness programme. There was opacification of the right lower thorax. Computed tomography and venography demonstrated an incidental right Bochdalek hernia with interruption of the inferior vena cava (IVC) and hepatic venous collateral continuation. The association of a Bochdalek hernia with an anomaly of the IVC is rare, with only one case described in the literature.

\section{Case report}

A 36-year-old female underwent a routine medical evaluation as part of an employee wellness programme. She was diagnosed positive for human immunodeficiency virus (HIV) and was referred for a chest radiograph as part of a work-up to exclude pulmonary tuberculosis. The chest radiograph demonstrated opacification in the right lower chest (not shown). The differential diagnosis included an elevated right hemidiaphragm, a diaphragmatic hernia or a subpulmonic pleural effusion. She had an absolute CD4 count of $752 \times 10^{6} / \mathrm{L}$ and a slightly elevated aspartate transaminase (AST) of $42 \mathrm{U} / \mathrm{L}$ (normal range 13-35 U/L). Other biochemical markers were normal. A chest drain was inserted but as no fluid drained from the tube it was removed, and she was referred for further evaluation.

Contrast-enhanced computed tomography (CT) of the chest and abdomen demonstrated a posterior defect in the right hemidiaphragm with herniation of the liver into the thorax (see Figure 1). The intrahepatic component of the inferior vena cava (IVC) was interrupted and drained directly into a medial hepatic vein in the right lobe of the liver. The hepatic venous anatomy was distorted. It consisted of a collection of dilated, tortuous veins within the liver parenchyma. One of the hepatic veins drained directly into the right atrium (see Figure 2). The azygous vein was also enlarged (see Figure 3). The portal venous system was not affected. The findings were confirmed on a venography study of the IVC (see Figure 4). The final diagnosis was an incidental right-sided Bochdalek hernia associated with interruption of the IVC with continuation via the azygous vein and hepatic venous collaterals into the right atrium.

\section{Discussion}

The diaphragm develops at weeks 4-12 in embryogenesis and consists of four parts, namely the pleuroperitoneal folds, the transverse septum, the oesophageal mesentery and the muscular body wall. A posterior (Bochdalek) hernia represents a developmental defect in the pleuroperitoneal folds or failure of fusion between the pleuroperitoneal folds and the transverse septum. ${ }^{1}$ It was first described by Victor Alexander Bochdalek in 1867 and is the most common type of congenital diaphragmatic hernia. ${ }^{2}$ Left-sided Bochdalek hernias are more common than right-sided Bochdalek hernias, although patients may also present with bilateral Bochdalek hernias (which are very rare). ${ }^{3}$

Bochdalek hernias are usually detected in the neonatal period as the hernia causes compression of the lung parenchyma, which may cause respiratory distress and cyanosis. ${ }^{4}$ Bochdalek hernias were found to be asymptomatic in $14 \%$ of patients (usually in females with right-sided hernias) in a review conducted by Brown et al. ${ }^{3}$ They also found that $12 \%$ of patients with a Bochdalek hernia may have associated cardiac, pulmonary or gastrointestinal abnormalities but associated IVC abnormalities were not described.

The incidence of developmental abnormalities of the IVC is approximately $1 \% .^{5}$ The embryogenesis of the IVC is complex, involving the development, regression, anastomosis and replacement of 


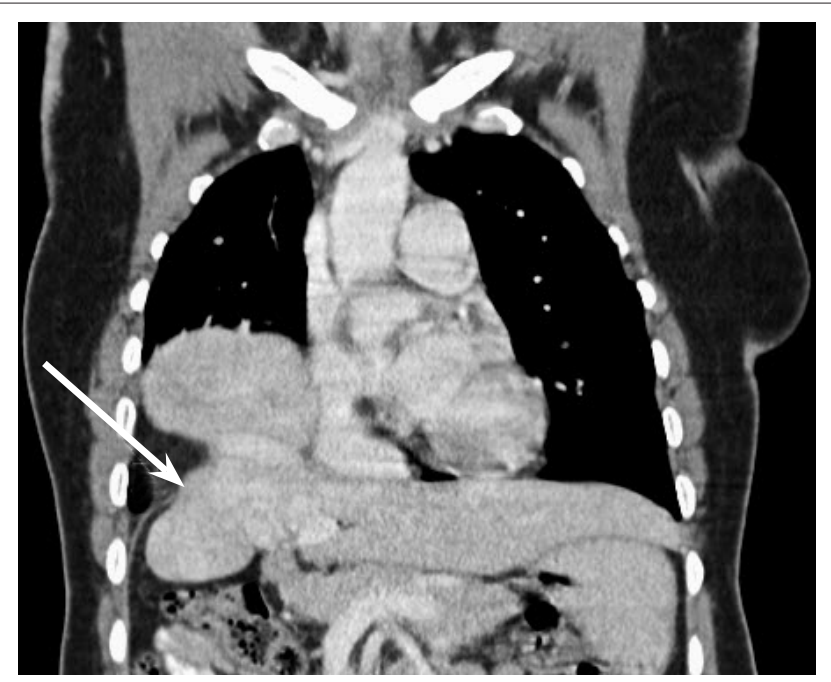

$\mathrm{CT}$, computed tomography

FIGURE 1: Coronal contrast-enhanced CT of the chest and upper abdomen demonstrating a defect in the posterior right hemidiaphragm (arrow) with herniation of the liver into the thoracic cavity, in keeping with a Bochdalek hernia. three pairs of venous channels, namely the posterior cardinal, subcardinal and supracardinal veins. ${ }^{5,6}$ By the seventh week of development in utero, the subcardinal venous system (also known as the retrohepatic segment of the IVC) is dominant. The right subcardinal vein and the hepatic vein fuse to form the prerenal segment of the IVC. Failure of this fusion results in the so-called interruption of the infrahepatic IVC. ${ }^{5}$ This results in the formation of collateral venous drainage, which commonly involves the azygous, hemi-azygous and portal venous system. Development of multiple intrahepatic veins (as in the case of our patient) occurs exceptionally, with only a few cases having being reported in the literature. Chevallier et al. found that a prerequisite for the formation of intrahepatic venous continuation is the presence of an inferior right hepatic vein, which is present in $10 \%$ of the population. It drains the right dorsolateral aspect of the liver directly to the IVC. ${ }^{6}$

The combination of a right-sided Bochdalek hernia together with interruption of the IVC and the formation of
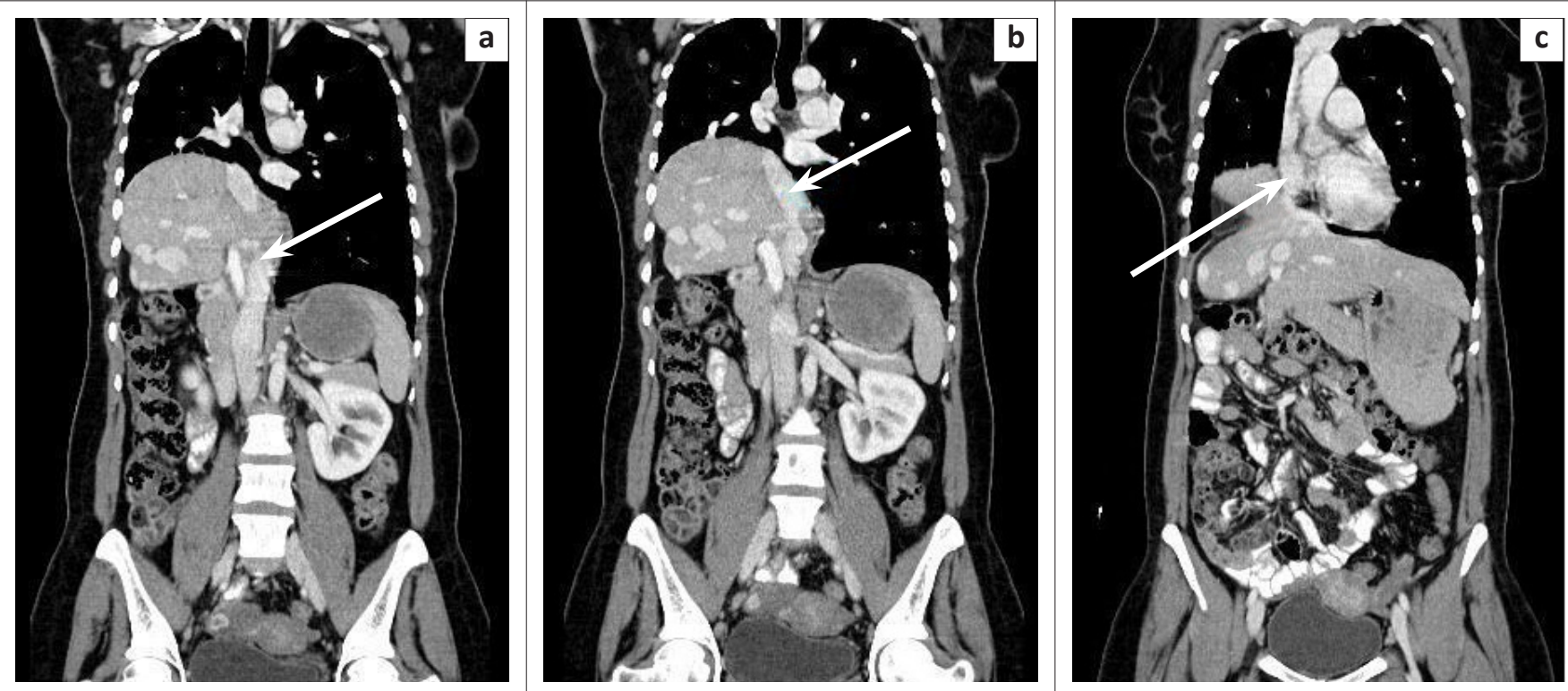

$\mathrm{CT}$, computed tomography; IVC, inferior vena cava.

FIGURE 2: Coronal contrast enhanced CT of the chest and abdomen which shows (a) the interrupted IVC (arrow) draining draining into (b) an enlarged hepatic vein in the medial right middle lobe which enters (c) the right atrium (arrow).

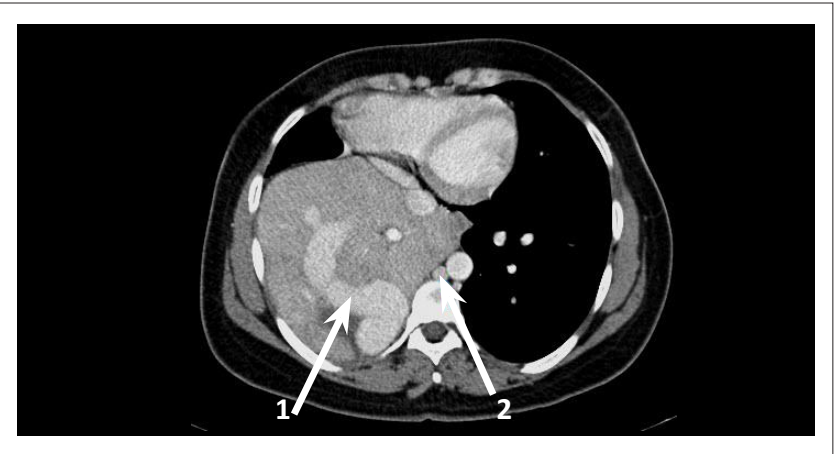

$\mathrm{CT}$, computed tomography.

FIGURE 3: Axial contrast-enhanced CT of the chest which demonstrates enlarged tortuous intrahepatic venous collaterals (arrow 1 ) and an enlarged azygous vein (arrow 2).

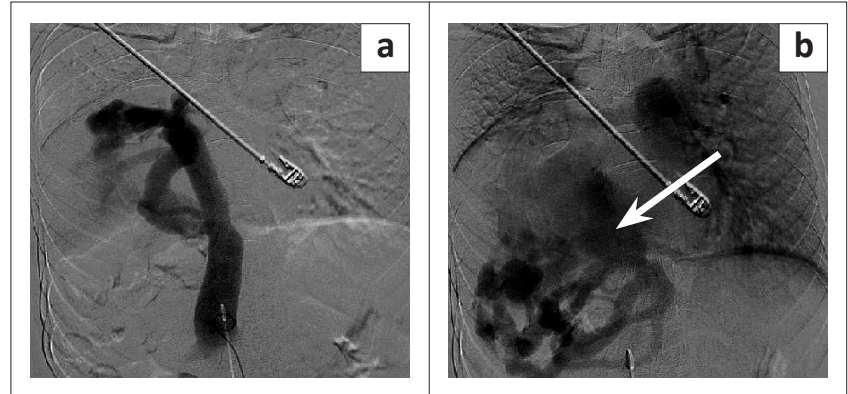

IVC, inferior vena cava.

FIGURE 4: Angiographic evaluation of the IVC. The catheter is placed within the infrahepatic IVC (a) with abrupt truncation of the IVC superiorly. Later phase of the study (b) shows filling of the distal interrupted IVC with draining of multiple hepatic venous collaterals, one of which drains into the right atrium (arrow). 
intrahepatic venous collaterals (as is presented in this case study) is extremely rare, with only one similar case having being reported in the literature. ${ }^{7}$

\section{Conclusion}

An adult patient presenting with the combination of a right-sided Bochdalek hernia and an interrupted IVC with hepatic venous collaterals, as described in this case report, is an extremely rare occurrence. Patients with Bochdalek hernias should always be investigated in order to exclude associated anomalies.

\section{Acknowledgements Competing interests}

The authors declare that they have no financial or personal relationship(s) that may have inappropriately influenced them in writing this article.

\section{Authors' contributions}

F.I.I. and R.H. (both from Steve Biko Academic Hospital and University of Pretoria) were initial contributors and main authors. A.C., F.I.I. and S.A. (from Steve Biko
Academic Hospital and University of Pretoria) were involved in the interventional radiology procedures and provided interpretation of the radiological images used in the article. P.N. and S.E. (both from Steve Biko Academic Hospital and University of Pretoria) provided clinical input and advice in write-up.

\section{References}

1. Nason LK, Walker CM, McNeeley MF, Burivong W, Fligner CL, Godwin JD. Imaging of the diaphragm: Anatomy and function. Radiographics. 2012:32:E51-E70. http://dx.doi.org/10.1148/rg.322115127

2. Temizöz $O$, Gençhellaç $H$, Yekeler $E$, et al. Prevalence and MDCT characteristics of asymptomatic Bochdalek hernia in adult population. Diagn Interv Radiol. 2010;16(1):52-55. http://dx.doi.org/10.4261/1305-3825.DIR.2750-09.1

3. Brown SR, Horton JD, Trivette E, Hofmann LJ, Johnson JM. Bochdalek hernia in the adult: Demographics, presentation, and surgical management. Hernia. 2011;15:23-30. http://dx.doi.org/10.1007/s10029-010-0699-3

4. Kinoshita $F$, Ishiyama $M$, Honda $S$, et al. Late-presenting posterior transdiaphragmatic (Bochdalek) hernia in adults: Prevalence and MDCT transdiaphragmatic (Bochdalek) hernia in adults: Prevalence and MDCT
characteristics. J Thorac Imaging. 2009;24:17-22. http://dx.doi.org/10.1097/

5. Balkanci F, Ozmen MN. Case report: Interruption of the inferior venal cava with anomalous intrahepatic continuation. Brit J Radiol. 1993:66:457-459. http:// dx.doi.org/10.1259/0007-1285-66-785-457

6. Chevallier P, Peten EP, Marcy P, Fabiani P, Diaine B, Padovani B. Inferior vena cava hypoplasia with intrahepatic venous continuation: Sonographic, angiographic and MR features including MR angiography. Clin Imaging. 1999;23:99-102. http:// dx.doi.org/10.1016/S0899-7071(99)00111-4

7. Mori M, Sakamoto T, Aoki S, et al. A case of Bochdalek hernia accompanied by complicated anomalies of the IVC and hepatic vein. [Case Reports, English Abstract, Journal Article]. Rinsho Hoshasen. 1988;33:495-498. 